\begin{abstract}
Iranica
Abstracta Iranica Revue bibliographique pour le domaine irano-aryen

Volume 40-41 | 2019

Comptes rendus des publications de 2017-2018
\end{abstract}

\title{
Yuka Kadoi (ed.). Persian Art: Image-Making in Eurasia
}

\section{Frantz Chaigne}

\section{OpenEdition}

1 Journals

\section{Édition électronique}

URL : http://journals.openedition.org/abstractairanica/51417

DOI : 10.4000/abstractairanica. 51417

ISBN : 1961-960X

ISSN : 1961-960X

Éditeur :

CNRS (UMR 7528 Mondes iraniens et indiens), Éditions de l'IFRI

Référence électronique

Frantz Chaigne, "Yuka Kadoi (ed.). Persian Art: Image-Making in Eurasia », Abstracta Iranica [En ligne], Volume 40-41 | 2019, document 25, mis en ligne le 30 décembre 2019, consulté le 19 avril 2021. URL : http://journals.openedition.org/abstractairanica/51417 ; DOI : https://doi.org/10.4000/ abstractairanica. 51417

Ce document a été généré automatiquement le 19 avril 2021.

Tous droits réservés 


\title{
Yuka Kadoi (ed.). Persian Art: Image- Making in Eurasia
}

\author{
Frantz Chaigne
}

\section{RÉFÉRENCE}

Yuka Kadoi (ed.). Persian Art: Image-Making in Eurasia. Edinburgh: Edinburgh University Press, 2018, 183 p., ISBN: 9781474411158

1 Le présent ouvrage rassemble les contributions de neuf auteurs au colloque "The Visual World of Persianate Culture », organisé à Édimbourg en 2014 par Yuka Kadoi. Le classement retenu suit une approche chronologique, de l'époque sassanide à des problématiques historiographiques contemporaines. Les aires géographiques s'étendent de l'Anatolie à l'Inde et la multiplicité des supports permet de saisir la richesse des arts matériels. Les deux premiers chapitres concernent l'époque sassanide: "The Visual Culture of Greater Iran: Some Examples of Kushano-Sasanian Art " (J. A. Lerner, 1-19) et "The Late Sasanian Figurative Capitals at Taq-i Bustan: Proposals regarding Identificationand Origins" (M. Compareti, 20-36). Les deux chapitres suivants abordent des aspects de la culture médiévale et prémoderne: " Architecture of the Wider Persian World: from Central Asia to Western Anatolia in the Twelth and Thirteenth Centuries» (R. P. McClary, 37-59) et «From Acquisition to Display: the Reception of Chinese Ceramics in the Pre-modern Persian World» (Y. Kadoi, 60-77). Viennent ensuite quatre contributions portant sur l'époque moderne: «Devotion and Protection: Four Amuletic Scrolls from Safavid Persia » (T. Nünlist, 78-101), « The Minarets of Hurmuzgan » (I. Szántó, 102-115), « Persian, Indian or IndoPersian? The Study of Sixteenth and Seventeeth Knotted Pile Carpets » (R. Santos, 116-132) et "The Calligraphic Art of Mishkin Qalam» (F. Stermotich-Cappellari, 133-156). Le dernier article, «The Kashan Mihrab in Berlin: a Historiography of Persian Lustreware» (M. Ritter, 157-178 / cr de cet article dans ce même volume d'Abstracta Iranica) permet quant à lui de mieux cerner les appropriations matérielles et les études menées en Occident et interroge aussi judicieusement dans sa conclusion sur la 
nécessité d'aborder de tels artefacts de façon plus contextualisée. Il convient de relever la quantité et la qualité de l'iconographie étayant chaque article, l'ouvrage comportant 59 illustrations en très grande partie en couleur, et la présence d'un index, certes assez bref mais tout à fait satisfaisant au vu de la construction de l'ouvrage.

\section{AUTEURS}

\section{FRANTZ CHAIGNE}

Chercheur associé, CNRS, Orient \& Méditerranée-«Islam médiéval» 